\title{
Statistical Analysis of the Wind Resources at the Importance for Energy Production in Bangladesh
}

\author{
M. Roungu Ahmmad ${ }^{1}$ \\ ${ }^{1}$ Department of Statistics, Jagannath University, Dhaka, Bangladesh \\ Email:m.roungu_sbi_du@yahoo.com
}

\begin{abstract}
Wind is an important source of renewable energy. Bangladesh being a tropical country which has a lot of wind flow at different seasons of the year. In this paper, wind power system with battery storage will be presented that can play electricity to our daily uses. Rayleigh distribution functions were considered and fitted to estimate of wind speed data. In our study, we studied previously collected data on the wind resources available in Bangladesh and by analyzing this data and have necessary accessory for application like wind power generation. The wind resources were mapped with the wind power density and the annual mean wind power estimated at, $194.2556 \mathrm{~W} / \mathrm{m}^{2}$ and $2351.76 \mathrm{Kh}$ and the annual mean wind speed $2.34635 \mathrm{kph}$ on $50 \mathrm{~m}$ heights and $R C L=0$.
\end{abstract}

Keywords: Rayleigh Probability Density, wind speed, wind energy

\section{Introduction}

The assessment of the wind resources at a given site is one of the preliminary steps in the sitting of a wind farm project. The assessment of the wind resources involves analyzing in detail the wind profile at a given height such as the wind speed and its prevailing direction, turbulence intensity, the shape and scale parameters, the wind distribution, wind power density and class etc. At a given site, a known wind power class is regarded as one of the approaches for assessing the wind resource of a given site. To determine the suitability of this site for wind energy generation; the mean wind speed, the shape and scale parameters of the site are estimated. The optimistic height from the ground is $40-70 \mathrm{~m}$, where the wind speed is high which is more applicable for wind energy generation [1]. The estimated shape and scale parameters are used alongside with the various statistical functions to model the wind speed, and the wind distributions which best describe the variation of the wind at the site are obtained. Once the wind distributions are obtained evaluation of the wind resources is conducted based on the known wind distribution for accurate sizing of the wind energy systems. The developed site wind power density is used to analyze the availability of wind energy generation for a known wind speed.

A number of studies have been conducted on the uses of probability density function for modeling of the wind speed around the world. Some of these density functions include Weibull, Rayleigh, Gamma, Lognormal, Exponential, and Gaussian etc.,2-5]. The Weibull function is widely used in the wind industry as the preferred approach for modeling of the wind speed for energy assessment due to its wide range of versatility, flexibility, and usefulness for describing the wind speed variation. It applicability can also be found in reliability engineering and life data analysis. Some authors, [6-8] suggested the Weibull distribution function as the best for modeling the wind speed at any site. In other research the wind speed data is efficiently fitted in Rayleigh probability distribution function [9]. So for 
our study we will estimate the wind speed and energy generation from wind speed using Rayleigh function which is more and more applicable in the situation of $50 \mathrm{~m}$ high air speed calculation belong to Bangladesh wind force data [9].

\section{Wind Prospect in Bangladesh}

Bangladesh is situated in the latitude between $20^{0} 34^{\prime}-26^{0} 38^{\prime} \mathrm{N}$ and longitude between $88^{0}$ $92^{0} \mathrm{E}$. The country has a $724 \mathrm{~km}$ long coastal ling long the Bay of Bengal, which belongs to Bangladesh. The wind blows over Bangladesh from March to September with a monthly average $3 \mathrm{~m} / \mathrm{s}$ to $6 \mathrm{~m} / \mathrm{s}$ [10]. The peak wind speed occurs during the months of June to July [10]. Park of wind turbines in coastal areas, can be incorporated in electricity grid on a substantial basis and could add reliability and consistency to the electricity generated by the Kaptai Hydro-electric power Station from March to September, during which load shedding becomes critical than winter season.

\section{Wind Data in Bangladesh}

The wind data Jan 2002 to Dec 2013 were selected at Dhaka Airport weather stations on a hub height $50 \mathrm{~m}$ above ground level as shown in table 1 . This time series wind data were continuously measured by the wind acquisition systems deployed on a measurement at this weather station. The wind data collected include the mean wind speed and direction, temperature, atmospheric pressure and air humidity. Here is shown the relationship between the wind availability and the speed of wind appendix Figure 1. From the Table 1 we see that the availability of wind is positively related with wind speed observed [11].

The wind speed varies continuously as a function of time and height and its assessing the wind resources potential of the locations. For longitudinal wind speed data we see that the wind speed of data is decreased gradually for different years. Most of the time the wind speed is high at month April - May and in year 2002-2005 is higher than others. We can conclude that from the data, the wind speed is decreasing day by day and change the weather belonging summer seasons.

\section{Modeling}

The wind speed variation at a given site is usually described by the wind density. Around the world, to identify the suitable statistical distribution for describing the wind speed variation, the following functions are been used and they include the Weibull [12], Rayleigh [13], Gamma [8, 14], Lognormal [15], Logistic [16-18] etc. However, the Weibull and Rayleigh functions are the widely accepted and extensively used statistical models for wind energy application. In this study, we consider the Rayleigh function because this function is a special case of the Weibull function. This function is found to typically model the wind speed at some sites where the Weibull function could not accurately modeled. At our wind site, where the value of $k$ is 2 , is commonly referred to as the Rayleigh function well fitted. At a wind site where the Weibull function is a poor model for fitting the wind speed, it may be appropriate to model the wind speed with a Rayleigh function [19].

\subsection{Rayleigh Probability Density}

Putting the value $\mathrm{k}=2$ into the probability distribution function of Weibull distribution of a continuous distribution is defined as Rayleigh distribution and is $f_{v}=\frac{2 v}{c^{2}} \exp \left[-(v / c)^{2}\right]$ Where $\mathrm{c}$ is the scale parameter at $\mathrm{k}=2$ and $\mathrm{f}_{\mathrm{v}}$ is the Rayleigh probability density function. 
And the cumulative density function is defined as $F_{v}=1-\exp \left[-(v / c)^{2}\right]$

The Rayleigh scale parameter $\mathrm{C}_{\mathrm{r}}$ is obtained using the maximum likelihood estimator as expressed in the given equation [20] $C_{r}=\sqrt{\frac{1}{2 N} \sum_{i=1}^{N} v_{i}^{2}}$ Where $C_{\mathrm{r}}$ is the Rayleigh scale parameter and $\mathrm{v}_{\mathrm{i}}$ is the wind speed observation at $\mathrm{i}^{\text {th }}$ time.

The mean of the Rayleigh distribution is defined by [19-20] $\bar{v}=C_{r} \sqrt{\frac{\pi}{2}} \quad$ (1) Where $\bar{v}$ is the mean of the distribution functions. From the above Fig2 we see that the fitted Rayleigh average speed of wind is always positively correlated $(\mathrm{r}=0.99999146)$ with the actual wind speed and for chi square test ( $\chi^{2}=0.999455$ ) is significant (at 0.05 level of significance). So for our study, Rayliegh function is approximately well fitted for our wind site data.

\subsection{Estimation of Wind Power Density}

The available wind power per unit swept are known as wind power density $\left(\mathrm{W} / \mathrm{m}^{2}\right)$ is defined as

$P=\frac{1}{2} \rho(h) V^{3}$, Where $V$ is the observed wind speed, $\rho(h)$ is the varied air density sweeping the rotor blades, and $\mathrm{P}$ is the wind power density. The theoretical maximum power $\{\mathrm{W}\}$ of wind that flows across the rotor swept are $\mathrm{A}$ at a given speed $V$ is given by $P_{0}=\frac{1}{2} \rho(h) A V^{3}$ Where $\mathrm{A}$ is the swept area and $\mathrm{P}_{0}$ is the theoretical wind power.

The mechanical power of the wind turbine is defined as $P_{m}=C_{p} \frac{1}{2} \rho(h) A V^{3}$

Where $\mathrm{P}_{\mathrm{m}}$ and $\mathrm{C}_{\mathrm{p}}$ are the mechanical power developed by the rotor blades and the power coefficient of the rotor, respectively. Based on the bertz law, the maximum wind power that can be extracted at any given time is $59 \%$ but in the practical design of the rotor blades, the maximum $\mathrm{Cp}$ values range from 0.2 to 0.4 [21]. The electrical power outputs $\{\mathrm{W}\}$ of the wind generator is defined as $P_{e}(v)=\eta_{R, G} * P_{m}$ Where $\eta$ is the efficiency of the gearbox and electrical generator which is always estimated or specified and $P_{e}(v)$ is the electrical power of the wind generator.

\subsection{Actual Power Density}

In this study the actual wind power density used in the study is estimate using below equation, the speed is obtained using the actual wind distribution, i.e., $v^{3}=\int_{0}^{\infty} v^{3} f(v) d v$. Using this the actual power generation is $P_{A}=\frac{1}{2} \rho(h) \int_{0}^{\infty} v^{3} f(v) d v$, Where $f(v)$ the actual wind distribution and $P_{A}$ is is the actual wind power density.

\subsection{Rayleigh Power Density}

The Rayleigh wind power density $\mathrm{P}_{\mathrm{R}}$ is estimated using the given equation below [24] $P_{R}=\frac{3}{\pi} \rho(h)(\bar{v})^{3}$

From the above equation (1), putting $\mathrm{k}=2 \quad \bar{v}=C_{r} \Gamma(1+.5)=C_{r} \Gamma(1.5)=C_{r} \sqrt{\frac{\pi}{4}}=$ $0.88662 * C_{r}$

Where $\bar{v}$ is the Rayleigh mean wind speed for $\mathrm{k}=2$, c is the Rayleigh scale parameter and $\mathrm{P}_{\mathrm{R}}$ is the wind power density, and density is redefined as $P_{R \text { (wind) }}=\frac{3 c}{\pi} \rho(h) \sqrt{\frac{\pi}{4}}$ 


\section{Result and Discussion}

The wind power potential at a given location is usually classified according to its wind power class. The wind power class of any given site ranges between classes 1 to 7 depending on the prevailing wind resources. A typically 10-40meters WPD estimates are suitable for small to medium scale wind energy system while a 50-meter WPD estimates are the industry standard metric used to gauge the site wind resource for large-scale wind energy systems. The criterion for the selection of the hub height(s) for the energy system depends mainly on the site wind resources and the associated capital cost. The wind resources at this site are mapped with the wind power density and the summary of the monthly mean wind power densities estimated at this site are shown.

From the Figure 1 and Table 1 we see that maximum wind density and power is extracted in month April to May in 2012-Dec 13 and wind power generation is $287.575 \mathrm{~W} / \mathrm{m}^{2}$ in Dhaka airport stations and on an average $P_{R \text { (wind) }}=699.32$ Watt. Then the power that can be extracted from wind assuming $25 \%$ turbine efficiency is $P_{\text {turbine }}=0.25 \times 699.32=$ 174.84 watts

\begin{tabular}{cccc}
\hline Year & Average Wind Speed & Average Cr & Wind Power $\boldsymbol{P}_{\boldsymbol{R}}=\frac{3 \boldsymbol{c}}{\boldsymbol{\pi}} \boldsymbol{\rho}(\boldsymbol{h}) \sqrt{\frac{\pi}{4}} \mathbf{W} / \mathbf{m}^{2}$ \\
\hline $2002-2005$ & 4.535833 & 3.2073 & 721.39 \\
$2005-2008$ & 4.0625 & 2.8726 & 705.55 \\
$2012-2013$ & 2.6525 & 1.873333 & 699.32 \\
\hline
\end{tabular}

Similarly we can estimate the optimum power of different stations in Bangladesh is Muhuri Dam, Feni 381.83 watt, Mognamaghat Cox's Bazar 456.75 watt, Parky Saikat Patenga 422.87 watt, Kuakata Patuakhali is 424.38 watt. And $25 \%$ turbine efficiency, then the usable energy in Muhuri Dam, Fenis 95.45 watt, Cox's Bazar 114.19 watt, Parky Saikat Patenga 105.72 watt,Kuakata Patuakhali is 106.09 wat. Total 592.29 watt. So on an average per station the potential energy is produced 119.258 watt.

Assuming that all wind installation is alone and total wind turbine is 19720 shows in table app2. So total wind power is generated in Bangladesh is approximately $2351.76 \mathrm{Kwatt}$.

\section{Cost Analysis}

From the analysis of different studies it is found that the price for producing per unit electricity from municipal solid waste by incineration would be between taka 9.50-10.50 (USD 0.136-0.150/unit) [27]. Where in Bangladesh, it is found that the electricity production cost for each unit of electricity from wind based power plant could be around taka 10.0012.00 (USD 0.142-0.171/unit), from diesel fired power plants is taka 8.00-14.00 (USD 0.1140.200 /unit) and Taka 8.00 (USD 0.114/unit) from furnace fired power units [28,29]

\section{Conclusion}

In this study assessments of wind characteristics for coastal region of Bangladesh ware made the following conclusion can be drawn

1. The shape factor $k=2$ and scale factor are determined for each month and it is found by Rayleigh functions is on an average 1.873333 which remains between 1.1 to 2.2.

2. The mean wind speed for each location is on an average is observed $2.6525 \mathrm{kph}$ and using Rayleigh function is estimated $1.873333 \mathrm{kph}$ which is less error.

3. Total estimated energy by wind turbine system is $2351.76 \mathrm{KWh}$. 
It can be an excellent, cost effective and also a reliable solution to mitigate the existing power crisis if we can implement the installation of more wind turbine in rural area as well as urban area in Bangladesh. It has a great impact on improving the socio-economic condition of rural people as well as will be a good sign of green energy technology.

Table 1. Wind Speed (kph) data and Data Availability (\%) from Dhaka Airport weather stations at 2002-13

\begin{tabular}{|c|c|c|c|c|c|c|c|c|c|c|c|c|}
\hline & Jan & Feb & $\begin{array}{c}\text { Ma } \\
\mathbf{r}\end{array}$ & Apr & $\begin{array}{c}\text { Ma } \\
\mathbf{y}\end{array}$ & Jun & Jul & $\begin{array}{c}\mathrm{Au} \\
\mathrm{g}\end{array}$ & Sep & Oct & Nov & Dec \\
\hline Jan-02 Dec & 2.9 & 3.5 & 555 & 7.2 & 691 & 6.2 & 6.5 & 491 & 3.6 & 3.0 & 1.7 & 2.3 \\
\hline 05 & 1 & 2 & 5.55 & 2 & 0.91 & 1 & 2 & 4.91 & 4 & 2 & 1 & 1 \\
\hline $\begin{array}{l}\text { Availabilit } \\
\text { y (\%) }\end{array}$ & 85 & 73 & 82 & 81 & 82 & 55 & 92 & 86 & 91 & 89 & 85 & 82 \\
\hline Jan 05 Dec & 2.6 & 3.3 & 4.71 & 6.3 & 5.82 & 5.7 & 5.8 & 4.41 & 3.6 & 2.6 & 1.9 & 1.9 \\
\hline 08 & 2 & 1 & 4.11 & 1 & 5.02 & 1 & 1 & 4.41 & 1 & 1 & 2 & 1 \\
\hline $\begin{array}{l}\text { Availabilit } \\
\text { y }(\%)\end{array}$ & 87 & 82 & 86 & 86 & 79 & 66 & 87 & 88 & 88 & 88 & 90 & 82 \\
\hline $\begin{array}{l}\text { Jna12-Dec } \\
13\end{array}$ & $\begin{array}{c}1.9 \\
1\end{array}$ & $\begin{array}{c}2.5 \\
2\end{array}$ & 2.91 & $\begin{array}{c}4.1 \\
5\end{array}$ & 3.71 & $\begin{array}{c}3.2 \\
4\end{array}$ & $\begin{array}{c}1.9 \\
1\end{array}$ & 4.21 & $\begin{array}{c}2.6 \\
5\end{array}$ & $\begin{array}{c}2.4 \\
1\end{array}$ & $\begin{array}{c}1.1 \\
2\end{array}$ & $\begin{array}{c}1.0 \\
9\end{array}$ \\
\hline $\begin{array}{l}\text { Availabilit } \\
\text { y }(\%)\end{array}$ & 64 & 66 & 82 & 90 & 93 & 81 & 77 & 82 & 86 & 62 & 90 & 74 \\
\hline
\end{tabular}

Average value (January 2012 - December 2013): 2.6Kph (Sources DAWS, 2012 -13)

Table 2. Estimation of the scale parameter and average wind speed by using Rayleigh probability distribution function at January 2012 - December 2013 data [11]

\begin{tabular}{lcccc}
\hline \multicolumn{1}{c}{ Month } & Wind speed & $\begin{array}{c}\text { Scale parameter } \\
\boldsymbol{C}_{\boldsymbol{r}}\end{array}$ & Density fun $\boldsymbol{f}_{\boldsymbol{v}}$ & Average wind speed $\overline{\boldsymbol{v}}$ \\
\hline January & 1.91 & 1.35 & 0.283184 & 1.690875 \\
February & 2.52 & 1.78 & 0.214357 & 2.22945 \\
March & 2.91 & 2.05 & 0.184631 & 2.567625 \\
April & 4.15 & 2.93 & 0.130043 & 3.669825 \\
May & 3.71 & 2.62 & 0.145539 & 3.28155 \\
June & 3.24 & 2.29 & 0.166931 & 2.868225 \\
July & 1.91 & 1.35 & 0.283184 & 1.690875 \\
August & 4.21 & 2.97 & 0.127985 & 3.719925 \\
September & 2.65 & 1.87 & 0.083441 & 2.342175 \\
October & 2.41 & 1.71 & 0.126163 & 2.141775 \\
November & 1.12 & 0.79 & 0.08094 & 0.989475 \\
December & 1.09 & 0.77 & 0.09568 & 0.964425 \\
\hline Average & $\mathbf{2 . 6 5 2 5}$ & $\mathbf{1 . 8 7 3 3 3 3}$ & $\mathbf{0 . 1 6 0 1 7 3}$ & $\mathbf{2 . 3 4 6 3 5}$ \\
\hline
\end{tabular}


Table 3. Estimation of Mean Square Error

\begin{tabular}{lccc}
\hline \multicolumn{1}{c}{ Month } & Wind speed & Average wind speed $\overline{\boldsymbol{v}}$ & Mean Square Error \\
\hline January & 1.91 & 1.690875 & 0.048016 \\
February & 2.52 & 2.22945 & 0.084419 \\
March & 2.91 & 2.567625 & 0.117221 \\
April & 4.15 & 3.669825 & 0.230568 \\
May & 3.71 & 3.28155 & 0.183569 \\
June & 3.24 & 2.868225 & 0.138217 \\
July & 1.91 & 1.690875 & 0.048016 \\
August & 4.21 & 3.719925 & 0.240174 \\
September & 2.65 & 2.342175 & 0.094756 \\
October & 2.41 & 2.141775 & 0.071945 \\
November & 1.12 & 0.989475 & 0.017037 \\
December & 1.09 & 0.964425 & 0.015769 \\
\hline
\end{tabular}

Table 4. Monthly Mean Wind Power Densities and its errors at Jan 2012-Dec 2013

\begin{tabular}{|c|c|c|c|c|}
\hline \multirow[b]{2}{*}{ Month } & \multirow[b]{2}{*}{ Wind speed } & \multicolumn{3}{|c|}{ Wind Power } \\
\hline & & Scale parameter $C_{r}$ & $P_{R}=\frac{3 c}{\pi} \rho(h) \sqrt{\frac{\pi}{4}} \mathrm{~W} / \mathrm{m}^{2}$ & Mean Square Error \\
\hline January & 1.91 & 1.35 & 139.9884 & 0.048016 \\
\hline February & 2.52 & 1.78 & 184.5774 & 0.084419 \\
\hline March & 2.91 & 2.05 & 212.575 & 0.117221 \\
\hline April & 4.15 & 2.93 & 303.8268 & 0.230568 \\
\hline May & 3.71 & 2.62 & 271.6813 & 0.183569 \\
\hline June & 3.24 & 2.29 & 237.4619 & 0.138217 \\
\hline july & 1.91 & 1.35 & 139.9884 & 0.048016 \\
\hline August & 4.21 & 2.97 & 307.9746 & 0.240174 \\
\hline September & 2.65 & 1.87 & 193.9099 & 0.094756 \\
\hline October & 2.41 & 1.71 & 177.3187 & 0.071945 \\
\hline November & 1.12 & 0.79 & 81.91916 & 0.017037 \\
\hline December & 1.09 & 0.77 & 79.84526 & 0.015769 \\
\hline Average & 2.6525 & 1.873333 & 194.2556 & 0.103474 \\
\hline \multicolumn{5}{|c|}{ 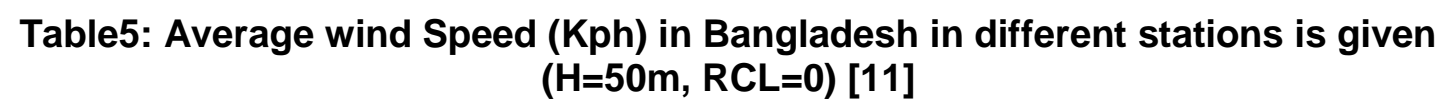 } \\
\hline & & $\begin{array}{l}\text { Muhuri Dam, } \\
\text { Feni }\end{array}$ & $\begin{array}{c}\text { Parky Saikat } \\
\text { Patenga, Chittagong }\end{array}$ & Kuakata Patuakhali \\
\hline \multicolumn{2}{|c|}{$\begin{array}{l}\text { Annual Average Wind } \\
\text { Speed }\end{array}$} & 1.805 & 1.868 & 1.871 \\
\hline
\end{tabular}




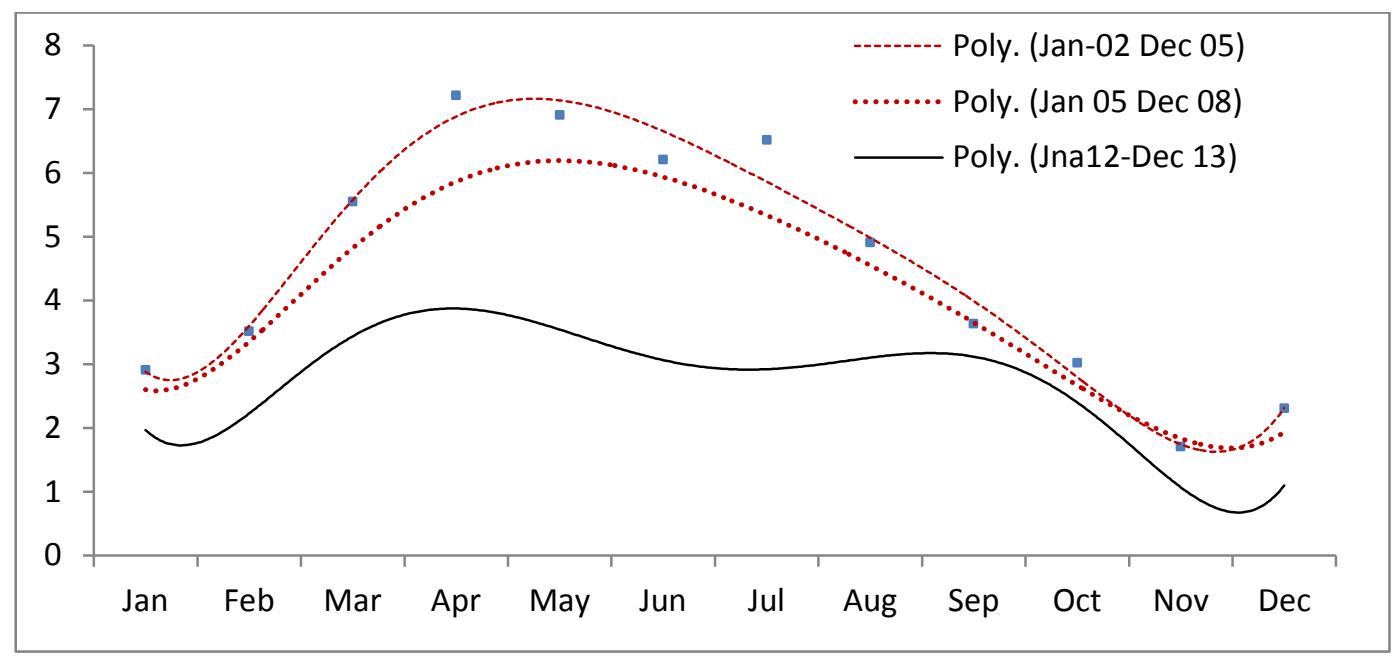

Figure 1. Comparison of the Monthly Mean Wind Speed Variation in Dhaka Airport Station, Bangladesh

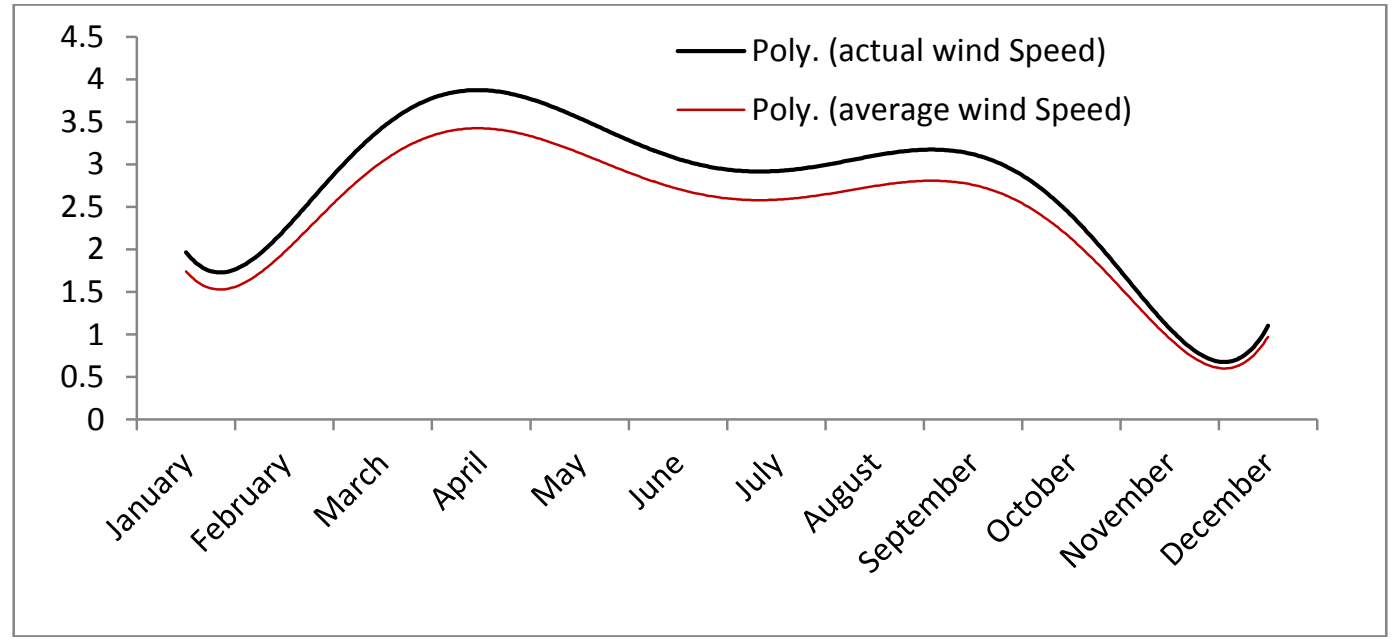

Figure 2. Comparison between Fitted and Actual Wind Speed

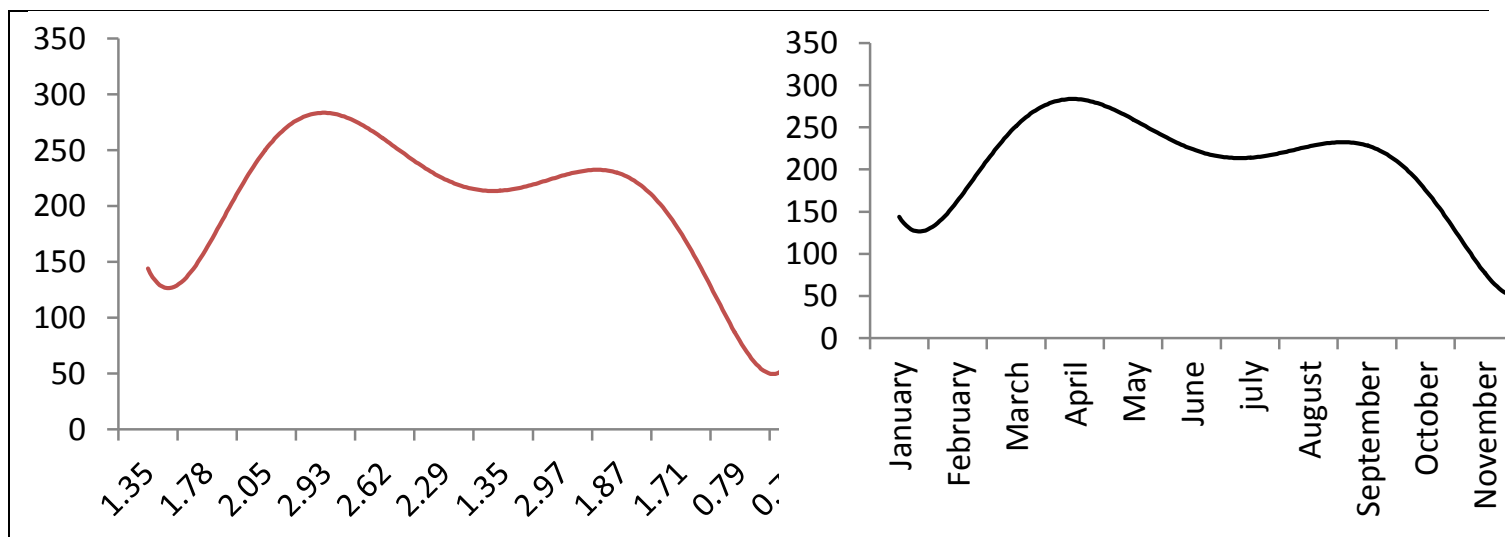

Figure 3. Power Generation for Different Scale Parameter and Month Of the Year 

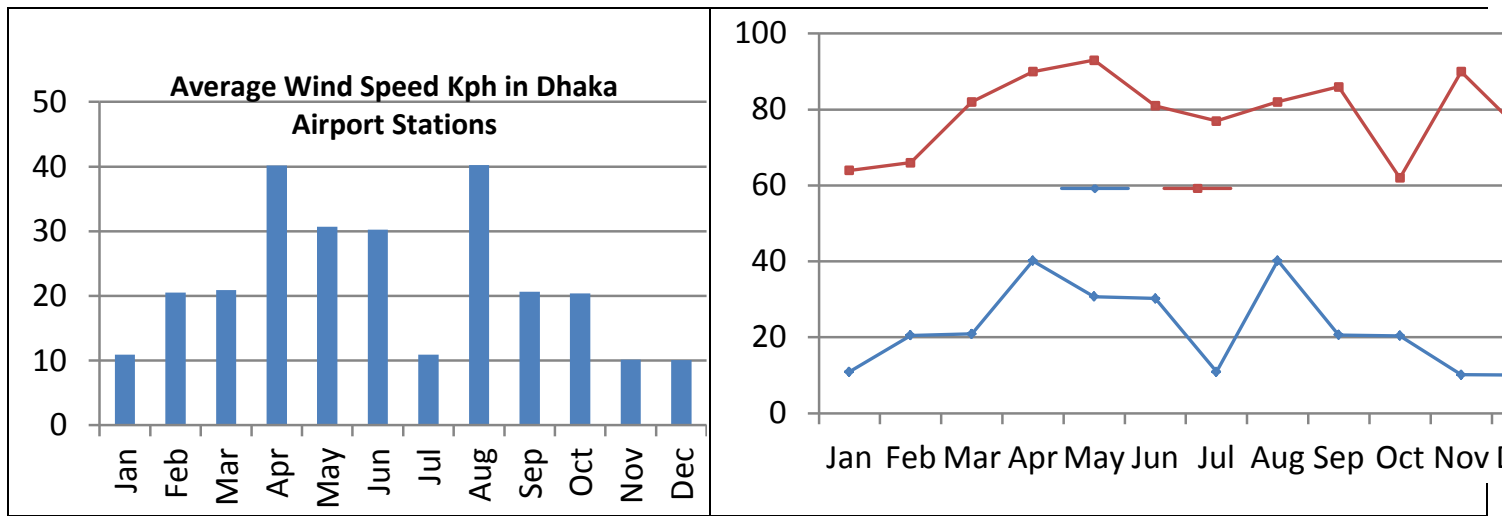

Jan Feb Mar Apr May Jun Jul Aug Sep Oct Nov [

Figure app1. Comparison of the monthly mean wind speed variation and data availability\% in Dhaka airport station, Bangladesh for the year January 2012December 2013

Table app2: Wind turbine installations in Bangladesh by different Organization [27]

\begin{tabular}{l|l|l|l|l}
\hline name & $\begin{array}{l}\text { Type of } \\
\text { Application }\end{array}$ & $\begin{array}{l}\text { Installed } \\
\text { Capacity(Watt) }\end{array}$ & Location & Present Status \\
\hline \multirow{2}{*}{ Grameen Shakti } & 3 Hybrid & 4,500 & $\begin{array}{l}\text { Grameen Offices in } \\
\text { the Coastal Region }\end{array}$ & Functioning \\
& Hybrid & 7,500 & $\begin{array}{l}\text { Cyclone Shelter in the } \\
\text { Coastal Region }\end{array}$ & Functioning \\
\hline BRAC & Stand-alone & 900 & Coastal Region & Functioning \\
\hline Bangladesh Army & Hybrid & 4,320 & Coastal Region & Functioning \\
\hline IFDR & Stand-alone & 400 & Chittagong Hill Tracts & Functioning \\
\hline & Stand-alone & 1,100 & Teknaf & Functioning \\
\hline LGED & Stand-alone & 600 & Meghnaghat & Functioning \\
\hline Total & $\begin{array}{l}\text { Wind-PV } \\
\text { Hybrid }\end{array}$ & 400 & Kuakata & Functioning \\
\hline
\end{tabular}

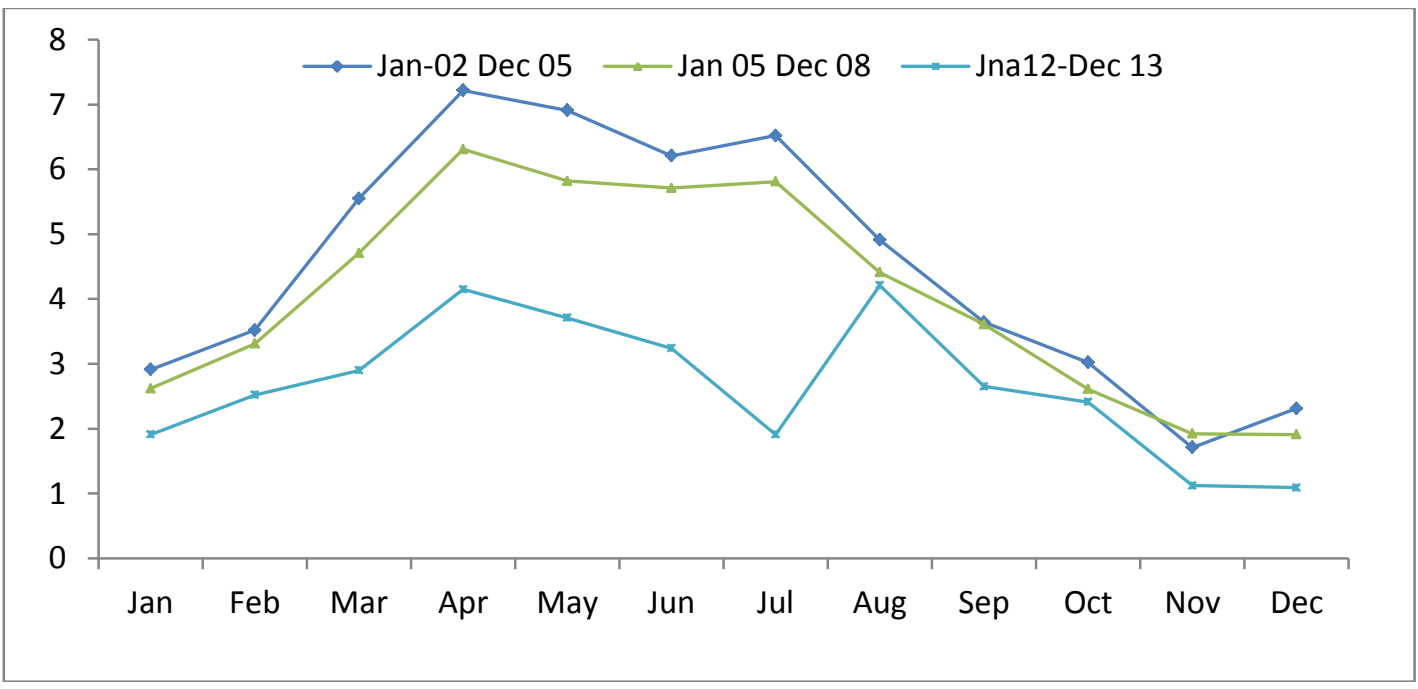

Figure app2. Wind Speed in Different Months in Different Years 


\section{References}

[1] Roy A., "Reliable estimation of Density Distribution in Potential Wind Power Sites of Bangladesh", International journal of Renewable energy Research, Vol. 2 No. 2, 201

[2] J. Waewsak, C. Chancham, M. Landry and Y. Gagnon; "An Analysis of Wind Speed Distribution at Thasala, Nakhon Si Thammarat, Thailand", Journal of Sustainable Energy \& Environment 2, p51-55, 2011

[3] I. Fyrippis, PJ. Axaopoulos, G. Panayiotou, "Analysis of wind Potential and Energy Production in Naxos Island, Greece", WSEAS Transactions on Power Systems, vol 3, Issue: 8, August 2008

[4] JP Hennesessey, "Some aspects of wind power statistics", Journal of Applied Meteorology 16, pp. 119-128, 1977.

[5] GA Torres, JL Prieto, and EDE Francisco, "A "Fitting wind speed distribution: A case study". Solar Energy 62(2): pp. 139-144, 1998.

[6] OS. Ohunakin "Wind characteristics and Wind energy Assessment in Uyo, Nigeria", Journal of Engineering and Applied Sciences 6 (2), pp. 141-146, 2011

[7] EK Akpinar, and S. Akpinar; "Statistical Analysis of Wind Energy Potentials on the basis of Weibull and Rayleigh Distributions for Agin-Elazig, Turkey", Journal of Power and Energy, Vol. 218, pp. 557-565, 2004.

[8] M. H. Albadi, EF. El-Saadany, and H. A. Albadi; "Wind to Power a New City in Oman", International Conference on Communication, Computer, And Power (ICCP'09), Muscat, February 2009

[9] Olaofe, Z. O., Folly K. A., "Statistical Analysis of the wind Resources at Darling for Energy Production", International journal of Renewable Energy Research, Vol. 2, No. 2, 2012.

[10] Ahmed, S., "Investigation and analysis of Wind Pumping system for Irrigation in Bangladesh", M.Sc Thesis, BUET, Dhaka, 2002.

[11] "Investigation and analysis of Wind Pumping system for Irrigation in Bangladesh", M.Sc Thesis, BUET, Dhaka, 2002.

[12] T.R. Ayodele, A.A. Jimoh, J.L Munda and J.T. Agee, "Empirical modeling of wind speed in wind energy applications: the case study of Port Elizabeth", Southern African Universities Power Engineering Conference, SAUPEC 13-15th July, 2011

[13] ZO. Olaofe, and K.A. Folly; "Wind Energy Analysis on the basis of Rayleigh Distribution for Darling City, South Africa", International Conference on Renewable Energy, Generation and Application, March 2012

[14] RK Panda, TK Sarkar, and AK Bhattacharya "Stochastic study of wind energy potential in India", Energy 15(10): pp. 921-930, 1990

[15] GA Torres, JL Prieto, and EDE Francisco, "Fitting wind speed distribution: A case study". Solar Energy 62(2): pp. 139-144, 1998.

[16] GR Justus CG "Physical climatology of solar and wind energy", Singapore: World Scientific. AWS Scientific, Inc. pp. 321-76, 1996

[17] E. Scerri and R. Farrugia, "Wind data evaluation in the Maltese Islands", Renewable Energy, (7), pp. 109114. 1996

[18] Olaofe, Z. O, Folly, K. A., " Statistical Analysis of the wind Resources at Darling for Energy Production”, International journal of Renewable Energy Research, Vol. 2 No. 2, 2012

[19] RK Panda, TK Sarkar, and AK Bhattacharya "Stochastic study of wind energy potential in Bangladesh", Energy 15(10): pp. 921-930, 2010

[20] K. Krishnamoorthy., Handbook of Statistic, University of Louisiana at Lafayette, by Taylor \& Francis Group, LLC, U.S.A. c 2006

[21] K. Krishnamoorthy., Handbook of Statistic, University of Louisiana at Lafayette, by Taylor \& Francis Group, LLC, U.S.A. c 2006

[22] Matlab R2010a, version 7.10.0.499.

[23] MR. Patel; "Wind and solar power systems, design, analysis and operation", 2nd edition, CRC Press PLC, New York, U.S.A, 2006.

[24] AN Celik, "A statistical analysis of wind power density based on the Weibull and Rayleigh models at the southern region of Turkey", Renewable Energy, 29, pp. 593-604, 2003

[25] Potentials of Wind Energy in Bangladesh (http://www.weatheronline. co.uk/ weather/ maps/ city

[26] Renewable Energy Prospects \& Trends in Bangladesh Presented by-Mazharul Islam. Bangladesh Power Development Board.

[27] BEN, 2009; Ahsan, 2011

[28] Bangladesh power Development Board, Annual Report of 2006-07, Dhaka: BPDB, 2008, available: www.bpbd.gov.bd/download/anual\%20Report-10.pdf

[29] Ahmed MF and Rahman MM (2000), water supply and sanitation: rural and low-income urban communities, ITN-Bangladesh, Dhaka. 
International Journal of $\mathrm{u}-$ and $\mathrm{e}-$ Service, Science and Technology

\section{Author}

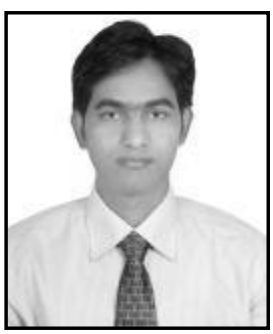

M. Roungu Ahmmad

Author's profile: Assistant Professor, Department of Statistics, Jagannath University, Dhaka-1100, Bangladesh.

Research Interest: Statistical Computing of Renewable energy, Environmental Statistics, Statistical Quality Control, Sampling Methods, Biostatistics and Informatics, Design and analysis of experiments etc. 